\title{
Keanekaragaman Jenis Bambu di Gunung Ciremai Jawa Barat
}

\author{
TRI CAHYANTO ${ }^{1}$, DHYNI ARIGUSTIN ${ }^{1}$, MUHAMMAD EFENDI $^{2}$ \\ ${ }^{1}$ Jurusan Biologi, Fakultas Sains dan Teknologi, Universitas Islam Negeri Sunan Gunung Djati \\ Bandung \\ Jl. AH. Nasution 105, Bandung 40614 \\ email: cahaya_trimau@yahoo.com; arigustin17.dhyni@gmail.com \\ ${ }^{2}$ Balai Konservasi Tumbuhan Kebun Raya Cibodas - Lembaga Ilmu Pengetahuan Indonesia \\ J1. Kebun Raya Cibodas PO.BOX 19 Sindanglaya, Cipanas, Cianjur, Jawa Barat 43253 \\ email: muhammadefendi05@gmail.com
}

\begin{abstract}
Mountain Ciremai as in situ conservation, reserve species of bamboo were used for variously of daily needs to handy craft. As the land changes and the increasing a need for bamboo by society, the existence of natural bamboo threatened that an inventory of natural bamboo species needs to be done. This study aims to list the species diversity and abundance of bamboo in Mountain of Ciremai West Java. Sampling is done using qualitative descriptive method which includes exploration, sampling, morphological observation and identification of the type of bamboo and measurement of environmental factors. Data obtained were then analyzed using the Shannon-Wiener diversity index to find out the diversity index species of bamboo in the area Mountain of Ciremai West Java. Based on data collection in the field, found 10 bamboo species namely G. apus J.A \& J. H. (shultes) Kurz, S. Silicatum Widjaja, G. pseudoarundnacea (Stard) Widjaja, B. Lako Widjaja, B. blumeana J. A \& J. H, S.Brachyladum Kurz, G. AtterHassk. Kurz, D. asper (Schult) Backer ex Heyne, D. aspervar. Thai, B. vulgaris Schard. ex J.C. The type most often found is G. apus J.A \& J. H. (Shcultes) Kurz, while the highest abundance was found in D. asper (Schult) Backer ex Heyne 2,500 clump. Based on the calculation of diversity indices in the area Mountain of Ciremai Kuningan relatively low level $\mathrm{H}^{\prime}=0.902164$ where $\mathrm{H}^{\prime}<1.5$. S.brachyladum is belongs to rare species.
\end{abstract}

Keywords: Bamboo, diversity, D. asper, S. Brachycladum, Mt. Ciremai West Java

\section{INTISARI}

Gunung Ciremai sebagai kawasan konservasi in situ menyimpan berbagai jenis bambu yang banyak dimanfaatkan dalam berbagai kebutuhan sehari-hari hingga industri anyaman. Seiring perubahan lahan dan meningkatnya kebutuhan akan bambu oleh masyarakat, keberadaan bambu di alam terancam sehingga re-inventarisasi jenis bambu alam perlu dilakukan. Tujuan dari penelitian ini yaitu mendata keanekaragaman jenis dan kelimpahan bambu di Gunung Ciremai Jawa Barat. Pengambilan sampel dilakukan dengan menggunakan metode deskriptif kualitatif yang meliputi eksplorasi, pengambilan sampel, pengamatan morfologi dan identifikasi jenis bambu dan pengukuran faktor lingkungan.

Kata Kunci: keanekaragaman, D. asper, S. brachycladum, Gunung Ciremai Jawa Barat.

\section{PENDAHULUAN}

Keberadaan bambu sepertinya tidak lepas dari kehidupan masyarakat. Bagi masyarakat pedesaan, bambu dimanfaatkan untuk bahan bangunan rumah, pagar, jembatan, ataupun bahan kerajinan karena batang yang kuat, lentur, lurus dan ringan (Winoyo et al., 2012). Dalam kehidupan modern, bambu dimanfaatkan untuk produk-produk dekoratif, alat rumah tangga, bahan bangunan, bahan alat kesenian dan lain-lain. Secara ekologis, bambu berperan dalam upaya konservasi tanah dan air karena memiliki sistem perakaran rapat sehingga dapat mencegah erosi tanah (Budi et al., 2006). Bambu tali misalnya, telah lama dimanfaatkan oleh 
masyarakat Bali sebagai obat tradisional berdasarkan lontar usada (kitab pengobatan tradisional Bali) untuk mengobati kencing manis, kencing batu, maag, sakit kuning (liver), hipertensi, ginjal, kanker payudara, limpa, kanker darah, dan batuk. Buluh bambu tali juga digunakan untuk meremajakan kulit bekas luka, memperlancar persalinan, dan mengobati panas (Sujarwo et al., 2010).

Keberadaan beberapa jenis bambu di alam mulai terancam karena over eksploitasi, perubahan fungsi lahan maupun kebakaran lahan terutama jenis bambu yang bernilai ekonomi (Zulkarnaen dan Wardani, 2015). Beberapa jenis bambu merupakan sumber daya melimpah dengan keanekaragaman yang cukup tinggi. Namun, kenyataannya masih banyak jenis bambu yang belum dikenal oleh masyarakat dengan baik (Budi et al., 2006), sehingga pembaharuan data keanekaragaman dan kelimpahan jenis bambu dari berbagai kawasan sangat diperlukan. Salah satunya di Kawasan Gunung Ciremai Kabupaten Kuningan.

Kabupaten Kuningan merupakan salah satu sentra industri kerajinan bambu. Jenis bambu tersebut diduga berasal dari kawasan Gunung Ciremai. Kebakaran hutan yang sering terjadi di Gunung Ciremai diduga turut menurunkan keragaman jenis bambu. Oleh karena itu, tujuan dari penelitian ini adalah menginventarisasi dan menganalisis kelimpahan serta persebaran jenis bambu yang ada di Kawasan Gunung Ciremai Kabupaten Kuningan Jawa Barat.

\section{METODE}

Penelitian dilakukan menggunakan metode deskriptif kualitatif pada dua jalur Resort Taman Nasional Gunung Ciremai, Kabupaten Kuningan Jawa Barat meliputi pengambilan sampel dan pengukuran faktor lingkungan, sedangkan pengamatan morfologi, identifikasi jenis dan analisis data dilakukan di Herbarium Biodjatiensis, Jurusan Biologi, Fakultas Sains dan Teknologi UIN Sunan Gunung Djati, Bandung.

Pengambilan sampel menggunakan metode eksplorasi pada kedua jalur meliputi Resort Pesawahan dan Resort Jalaksana. Pengambilan sampel dan pembuatan herbarium mengacu pada Balgooy (1987) dan Rugayah et al. (2004). Pengukuran faktor lingkungan dilakukan setiap rumpun bambu yang ditemukan meliputi lokasi geografi, persebaran bambu, habitat bambu, ketinggian tempat, kemiringan lahan, suhu, kelembaban, intensitas cahaya dan $\mathrm{pH}$ tanah. Pengamatan morfologi meliputi nama lokal jenis tumbuhan, nama ilmiah, jumlah rumpun bambu, buku-buku bambu, pelepah buluh, daun pelepah daun, bentuk percabangan, dan rembung. Identifikasi jenis bambu yang ditemukan mengacu pada Widjaja (1986; 2001) dan Arinasa \& Peneng, (2013). Tingkat keragaman jenis bambu di Gunung Ciremai Kabupaten Kuningan Jawa Barat dihitung dengan menggunakan persamaan indeks keragaman Shannon-Wiener yang mengacu pada (Kreb, 1989).

\section{HASIL}

Tabel 1. Jenis bambu dan persebarannya di blok Kawasan Taman Nasional Gunung Ciremai

\begin{tabular}{llcc}
\hline \multicolumn{1}{c}{ Nama Ilmiah } & \multicolumn{1}{c}{ Nama daerah } & Penyebaran & Jumlah rumpun \\
\hline Gigantochloa apus & Bambu tali & $1,3,4,5,6,7$ & 445 \\
\hline Schizostachyum silicatum & Awi tamiyang & $1,2,7$ & 153 \\
\hline Gigantochloa pseudoarundinacea & Awi Surat & 6,7 & 25 \\
\hline Bambusa lako & Bambu hideung & 3 & 2 \\
\hline Bambusa blumeana & Haur cucuk & 1 & 1 \\
\hline Schizostachyum brachyladum & Awi tamiyang wuluh & 6 & 7 \\
\hline Gigantochloa atter & Bambu temen & $1,2,3,4,6$ & 207 \\
\hline Dendrocalamus asper & Awi bitung & 5 & 2.500 \\
\hline Dendrocalamus aspervar.thai & Awi petung & 6 & 10 \\
\hline Bambusa sp. & Haur & 6 & 11 \\
\hline Bambusa vulgaris & Awi ampel & 6 & 5 \\
\hline Jumlah & & & 3.376 \\
\hline
\end{tabular}


Keterangan: 1. Blok Sumur; 2. Blok Sangkanerang; 3. Blok Pajambon; 4. Blok Gunung Putri; 5. Blok Gongseng; 6. Blok Panyusupan; 7. Blok Ganda

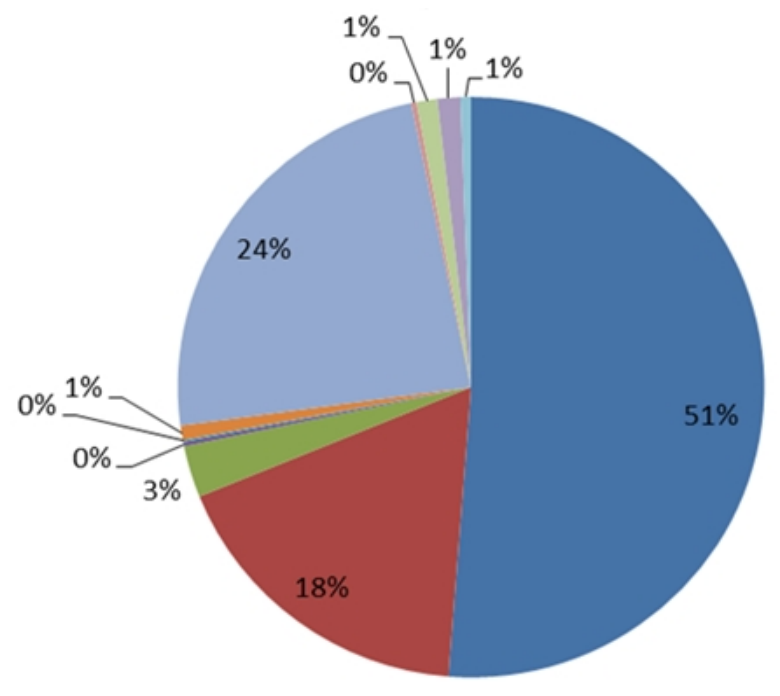

- Gigantochloa apus J.A \& J. H. (shultes) Kurz

- Schizostachyum silicatum Widjaja

- Gigantochloa pseudoarundnacea (Stard Widjaja)

- Bambusa lako Widjaja

- Bambusa blumeana J. $A$ \& $J . H$

- Schizostachyum brachyladum Kurz

- Gigantochloa atter Hassk. Kurz

- Dendrocalamus asper (Schult) B acker Ex Heyne

- Dendrocalamus asper var. Thai

- Bambusa sp

- Bambusa vilgaris Schard. Ex J.C

Gambar 1. Persentase Jenis-jenis Bambu di Kawasan BTNGC

Tabel 2. Persebaran dan jenis bambu pada berbagai ketinggian di TNGC

\begin{tabular}{|c|c|c|c|}
\hline 500-750 m dpl & $750-1000 \mathrm{~m} \mathrm{dpl}$ & $1000-1250 \mathrm{~m}$ dpl & 1250-1500 m dpl \\
\hline Gigantochloa apus & Gigantochloa apus & - & Gigantochloa apus \\
\hline Gigantochloa atter & Gigantochloa atter & - & Gigantochloa atter \\
\hline Dendrocalamus asper & Dendrocalamus asper var. thai & & \\
\hline Schizostachyum silicatum & Schizostachyum brachyladum & & \\
\hline Gigantochloa pseudoarundinacea & Gigantochloa pseudoarundinacea & & \\
\hline \multirow[t]{3}{*}{ Bambusa vulgaris } & Bambusa blumeana & & \\
\hline & Bambusa lako & & \\
\hline & Bambusa sp. & & \\
\hline
\end{tabular}

Tabel 3. Hasil perhitungan Indeks keragaman bambu di kawasan BTNGC

\begin{tabular}{|c|c|c|c|c|c|}
\hline Nama Ilmiah & Nama Daerah & $\begin{array}{l}\text { Jumlah } \\
\text { Rumpun }\end{array}$ & pi & In pi & pi Inpi \\
\hline $\begin{array}{l}\text { 1. Gigantochloa apus J.A \& J. H. (Shultes) } \\
\text { Kurz }\end{array}$ & Bambu tali & 445 & 0.1322 & -2.0234 & -0.2675 \\
\hline 2. Schizostachyum silicatum Widjaja & Awi tamiyang & 153 & 0.04545 & -3.091 & -0.1405 \\
\hline $\begin{array}{l}\text { Gigantochloa pseudoarundnacea (Stard) } \\
\text { Widjaja) }\end{array}$ & Awi Surat & 25 & 0.00743 & -4.9026 & -0.0364 \\
\hline 4. Bambusa lako Widjaja & Bambu hideung & 2 & 0.00059 & -7.4283 & -0.0044 \\
\hline $\begin{array}{l}\text { 5. Bambusa blumeana J. A \& J. H (Shultes) } \\
\text { Kurz }\end{array}$ & Haur cucuk & 1 & 0.0003 & -8.1215 & -0.0024 \\
\hline 6. Schizostachyum brachyladum Kurz & Awi tamiyang wuluh & 7 & 0.00208 & -6.1756 & -0.0128 \\
\hline 7. Gigantochloa atter Hassk. Kurz & Bambu temen & 207 & 0.0615 & -2.7888 & -0.1715 \\
\hline $\begin{array}{l}\text { 8. Dendrocalamus asper (Schult) Backerex } \\
\text { Heyne }\end{array}$ & Awi bitung & 2500 & 0.74272 & -0.2974 & -0.2209 \\
\hline 9. Dendrocalamus asper var. Thai & Awi petung & 10 & 0.00297 & -5.8189 & -0.0173 \\
\hline 10. Bambusa sp. & Haur & 11 & 0.00327 & -5.7236 & -0.0187 \\
\hline 11. Bambusa vulgaris Schard. ex J.C & Awi ampel & 5 & 0.00149 & -6.512 & -0.0097 \\
\hline
\end{tabular}




\begin{tabular}{|c|c|c|}
\hline Jumlah & 3366 & -0.9022 \\
\hline & & 0.90216 \\
\hline
\end{tabular}

\section{PEMBAHASAN}

Keragaman, Kelimpahan dan Persebaran Jenis Bambu di Taman Nasional Gunung Ciremai. Dari hasil inventarisasi, sebanyak 10 jenis termasuk ke dalam tiga marga bambu dicatat dari Kawasan Gunung Ciremai Kabupaten Kuningan. Dua jenis bambu yakni Bambusa blumeana dan Schizostachyum brachyladum merupakan jenis endemik di Jawa. Bambusa blumeana ditemukan tumbuh pada Blok Haurcucuk, sedangkan $S$. brachyladum yang terbanyak ditemukan pada Blok Ganda. Kedua jenis tersebut ditemukan pada keadaan habitat dengan lereng, dekat dengan sumber sumber mata air bagi warga.

Dari hasil penghitungan kelimpahan jenis bambu di kawasan Gunung Ciremai terdapat 3.376 rumpun bambu berhasil dicatat. Dendrocalamus asper merupakan jenis yang paling banyak ditemukan, sedangkan $B$. blumeana, $S$. brachycladum, B. vulgaris dan B. lako hanya ditemukan kurang dari 10 rumpun. Bahkan, B. blumeana hanya ditemukan sebanyak satu rumpun sehingga perlu dikonservasi secara ex situ, terutama di Kebun Raya Kuningan. Adapun presentase jenis bambu yang ditemukan disajikan dalam gambar 1.

Blok Panyusupan memiliki jenis bambu terbanyak yakni sebanyak tujuh jenis yaitu $G$. apus, G. pseudoarundinacea, Schizostachyum brachyladum, G. atter, Dendrocalamus asper var. thai, Bambusa vulgaris dan Bambusa sp. Gigantochloa apus tersebar di keenam blok penelitian terlihat pada Tabel 1.

Bambu di kawasan Taman Nasional Gunung Ciremai banyak ditemukan di pinggir sungai dan jurang walau ada pula yang ditemukan di dataran rendah. Menurut Dransfield dan Widjaja (1995) dan Arinasa (2014), bambu tersebar pada ketinggian 500 sampai $1500 \mathrm{~m}$ dpl. Kelimpahan bambu tertinggi pada ketinggian 750 sampai $1000 \mathrm{~m}$ dpl. Pada ketinggian tersebut, bambu tumbuh pada lereng perbukitan atau gunung dengan kemiringan $30^{\circ}$ sampai $80^{\circ}$ dengan kontur tanah bergelombang, sehingga berperan penting untuk mencegah longsor. Adapun persebaran bambu pada masing-masing kelompok ketinggian tersaji pada Tabel 2.

Pada ketinggian 1000-1250 m dpl di lereng Gunung Ciremai, rumpun bambu tidak ditemukan. Pada ketinggian tersebut lebih didominasi oleh tegakan pinus dan semak dengan tumbuhan berduri. Pada ketinggian 1250-1500 m dpl, G. apus dan $G$. atterkembali ditemukan. Kedua bambu tersebut memiliki penyebaran yang luas dan ditemukan hingga ketinggian $1400 \mathrm{~m}$ dpl. Hal tersebut sejalan dengan Widjaja (1986) yang menyatakan bahwa marga Gigantochloa memiliki persebaran luas dan berperan penting bagi masyarakat pedesaan. Pada umumnya jenis Gigantochloa digunakan sebagai bahan baku pembuatan rumah, bahan dasar anyaman, furniture, serta rebung dijadikan sebagai bahan makanan.

\section{Tingkat keragaman bambu} berdasarkan indeks keragaman ShannonWiener. Tingkat keragaman bambu di kawasan Gunung Ciremai dari dua resort penelitian berdasarkan indeks keragaman Shannon-Wiener didapatkan nilai H' sebesar 0,902164 . Nilai tersebut termasuk ke dalam tingkat keanekaragaman rendah $\left(H^{\prime}<1,5\right)$. Keanekaragaman jenis menggambarkan terjadinya tingkat keanekaragaman yang terdapat pada suatu kawasan. Nilai keanekaragaman jenis dipengaruhi oleh jumlah individu suatu jenis. Semakin tinggi nilai indeks keanekaragaman jenis, maka semakin banyak jenis yang terdapat pada area tersebut. Rendahnya tingkat keanekaragaman jenis bambu di kedua resort tersebut diduga berkaitan dengan menurunnya jumlah bambu akibat kebakaran hutan yang terjadi di Gunung Ciremai. Selain itu, bambu dikenal memiliki kecepatan tumbuh relatif lambat.

\section{KESIMPULAN}

Sebanyak 11 jenis bambu berhasil diinventarisasi dari Gunung Ciremai Kabupaten Kuningan, yaitu G. apus, S. 
silicatum, G. pseudoarundnacea, B. lako, B.blumeana, S. brachyladum, G. atter, D. asper, D. asper var. thai, Bambusa sp., dan B. vulgaris. Secara umum, keanekaragaman bambu di kawasan tersebut tergolong rendah dengan nilai H' sebesar 0,902164. Ke depannya $B$. blumeana dan jenis bambu yang tergolong langka lainnya perlu segera dikonservasi secara ex situ sehingga mempertahankan keberadaan jenis tersebut.

\section{UCAPAN TERIMA KASIH}

Penulis mengucapkan terima kasih kepada kepala BTNGC yang telah memberikan ijin penelitian di kawasan BTNGC, Ibu Nisa S. Febriyanti yang telah membantu perijinan selama penelitian. Kepala Resort Jalaksana, Kepala Resort Pasawahan, Bapak Mulyadi dan Bapak Supriyadi yang telah membantu dalam pengambilan sampel selama penelitian.

\section{DAFTAR PUSTAKA}

Arinasa IB, Peneng IN. 2013. Jenis-jenis Bambu di Bali dan Potensinya. Jakarta: LIPI Press. hal.119

Arinasa IBK. 2014. Studi Populasi Dinochloa sepang, Bambu endemik Bali. Buletin Kebun Raya 17(1): 1-7.

Arinasa IBK, Peneng IN. 2013. Jenis-Jenis Bambu di Bali dan Potensinya. Jakarta: LIPI press.
Budi I, Rahayuningsih SR, Kusmoro J. 2006. Keanekaragaman Jenis Bambu di Kabupaten Sumedang, Jawa Barat. Jakarta: Perpustaakan Nasional Indonesia. hal 1-51

Dransfield S, Widjaja EA (Ed). 1995. Plant Resources of South-East Asia-(Prosea) No.7 Bamboos. Leiden: Backhuys Publishers.

Sujarwo W, Arinasa IBG, Peneng IN. 2010. Inventarisasi Jenis-Jenis Bambu yang Berpotensi Sebagai Obat di Kabupaten Karangasem Bali. Bul.Littro. vol 21(2):129-137

Widjaja EA. 1986. Identikit Jenis-Jenis Bambu di Kepulauan Sunda Kecil. Bogor: Herbarium Bogoriense, Balitbang Botani, Puslitbang Biologi-LIPI.

Widjaja EA. 2001. Identikit Jenis-Jenis Bambu di Jawa. Bogor. Seri Panduan Lapangan. Bogor: Puslitbang Biologi LIPI.

Winoyo WW, Winarni, Winastuti DA, Aristiatmoko P. 2012. Sebaran dan potensi pemanfaatan bambu di Desa Purwobinangun Kecamatan Pakem Kabupaten Sleman Yogyakarta. Seminar Nasional Agroforestri III. 29 Mei 2012.

Zulkarnaen RN, Andila PS. 2015. Dendrocalamus spp: Bambu raksasa koleksi Kebun Raya Bogor. Prosiding Seminar Nasional Masy Biodiv Indon. vol 1(3):534-538. 